\title{
URBAN TRAFFIC PROBLEMS AND SOLUTIONS
}

\author{
Awari Mahesh Babu \\ Professor, Civil Engineering Department, Tirumala Engineering College, Hyderabad.TS. India. \\ maheshbabuawari@gmail.com
}

\begin{abstract}
Most of the urban metropolitan cities are facing traffic problems due delay and overcrowding. Recently the growth of population increased unusually because of the development and employment in metropolitan cities. Generally, road transportation is the major approach of convey which connects the villages, towns, cities, metropolitan regions, states and whole country in to the system establishing an innovative communiqué. It improves the entire nation development, environment surroundings and socio economic customs developments. Additionally the special advantages of the highway transport individual have been facing unusual troubles owing to the need of its suitable organization, refurbish \& preservation. With the unusual predicament of road transport, traffic delay and overcrowding are the rising troubles in the urban region. Various authentic problems and solutions of traffic delay and overcrowding have been discussed in this paper.
\end{abstract}

Keywords: Cities, Approach, Highway, Population, Nation

\section{INTRODUCTION}

Traffic overcrowding is the existence of delays by the side of a substantial lane owing to the existence of additional road users. This is the most important problem of transportation in metropolitan region. Because of this, each cause is delaying: road user insincerity achieve to the intention, be short of services on the period public require, be short of services scheduled the routes public necessitate. Owing to the traffic overcrowding in the unusual intersections the liberated stream of the vehicles speed is low compare to the design speed. This will effect socioeconomic development of the country. Environmental pollution increases due to traffic delay and overcrowding. The imbalance of physiological behavior of the road user may leads to the risk generation further it may leads to accident.

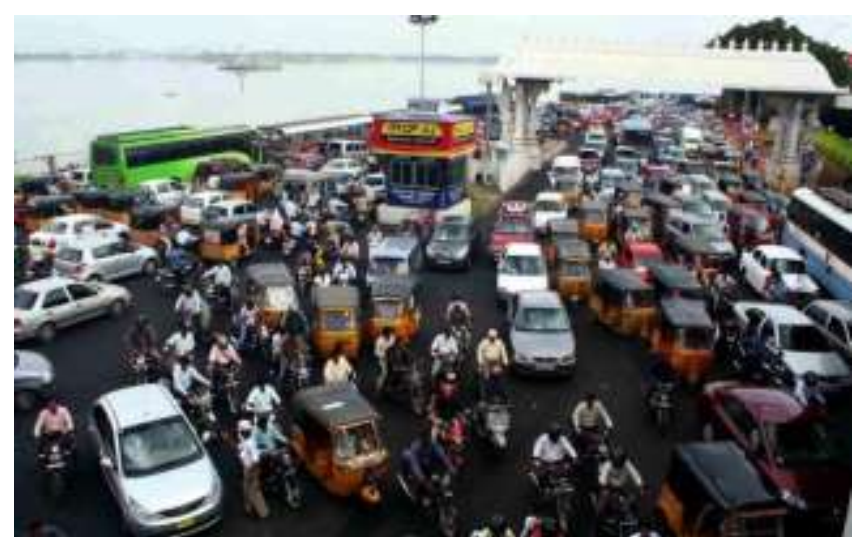

Fig 1. Traffic delay and overcrowded under mixed traffic conditions

\section{STUDY OF PROBLEMS}

All traffic delay and overcrowding is caused by overindulgence order. When the capability road exceeds, a wait in line will appearance. The wait in line is relatively perceptive to the quantity of intemperance order. Pro illustration, if it has needed off on a four-lane throughway is 7,300 vehicles / $\mathrm{hr}$ and the ability in a jam is also 7,300 vehicles/hr, we anticipate - redundant delay of vehicles within the intersections. $\neg$ Busy streets and amplified effluence caused by individual vehicle. Every Vehicle stop extended time in traffic since the quantity of vehicles on that region, consequently raising the quantity of moment spends scheduled the street. Irregular parking and mixed traffic conditions will lead to delay and overcrowding. Mixed traffic conditions in metropolitan region are very complex and they leads to delay and overcrowding. Slow moving vehicles like cycles, cycle rickshaws, Autos, bullock carts, heavy transport vehicles will also cause delay and overcrowding of traffic in metropolitan region. Apart from these political processions, dharnas, strikes, religion processions will effect traffic movement. Religion small temples, mosques, churches some of them are recently created by neighbor land owners (because land value will be more as compared to government compensation) and politician statues leads to delay and overcrowding in metropolitan region.

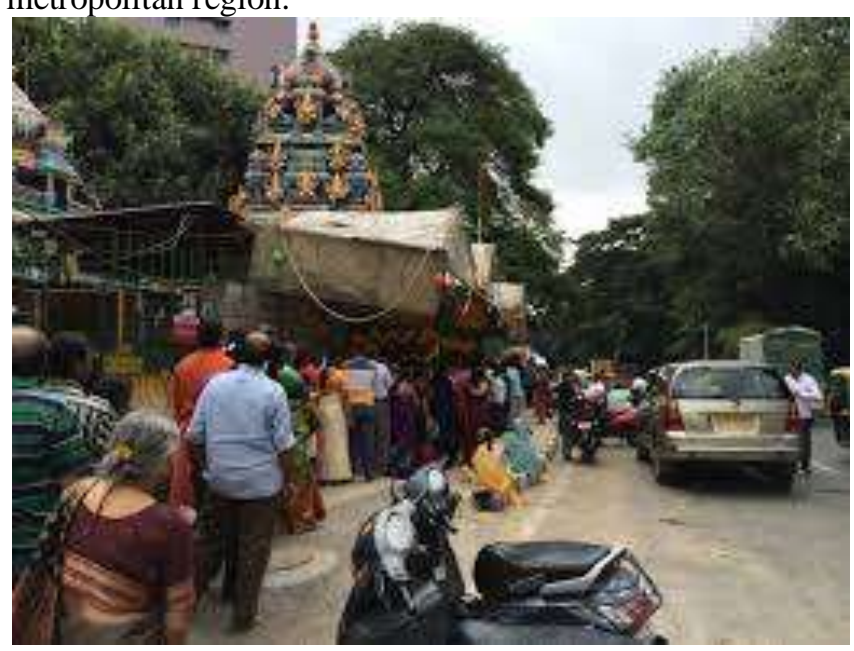




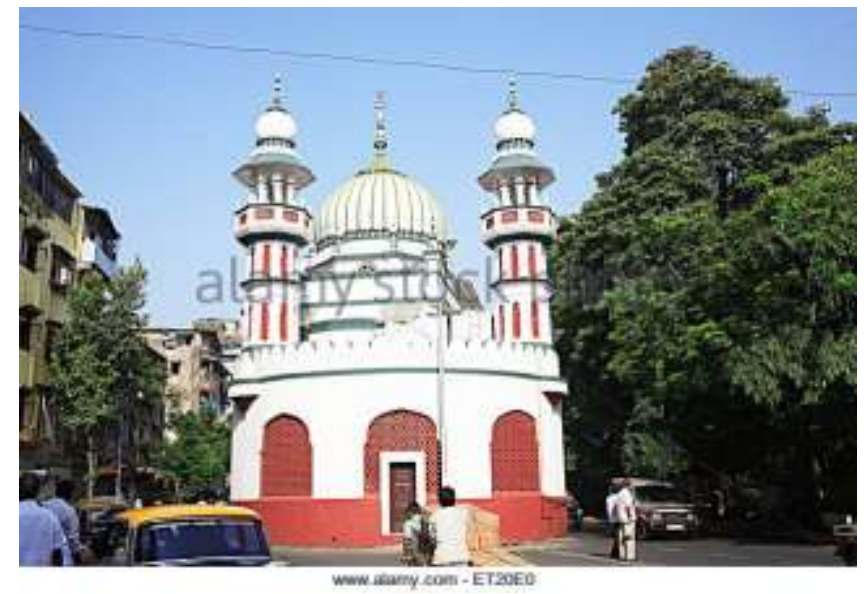

Hindrance to traffic on metropolitan region

\section{SOLUTIONS}

Evidently India, one of the most crowded nations in the globe, in addition a rapid increasing economy, is taking into consideration terrible traffic delay and overcrowding difficulty in its metropolitan area. A scientific approach is required to revise traffic delay and overcrowding providers/constraint. Application of mathematical models to traffic parameters should be implemented as there is constraint for road criterions and limited funds. Some of the following recommendations have been studied for improving traffic movement and to reduce delay and overcrowding in metropolitan region.

1. Separate traffic bays should be indentified for like category of vehicles i.e, two wheels vehicles, and three wheels vehicles, Bus tracks etc.,

2. Suitable parking places should be identified. Users have to park their vehicles at provided regions/bays.

3. Well planning shopping mall must be allowable in metropolitan region with proper parking area and other amenities.

4. Expand the road pavement and carriage way width to accommodate increased traffic vehicles.

5. Planning of series signal system and signal timings should be allocated as number of vehicles in queue on that lane.

6. Implementation of Intelligent Transportation System similar to confrontation organization, Corridor administration, sophisticated means of transportation arrangement, sophisticated traffic organize, genuine instance trip corresponding, incorporated passage \& reasonable arrangement.

7. Improvement of the street/gulley/local roads, use for two wheelers with speed breakers.

8. Superior walkway illumination, planned bus stops.

9. Appropriate administration of lighting organization on urban roads.

10. Strictly implement of traffic laws \& policy.

11. Encourage sharing vehicles/minibuses/cars /passenger vans

12. Flyovers/sky flyovers/Metro rails/Elevated express ways should be constructed.

13. Use side area (occupy the adjacent land owners) for the roads adjacent to religion small temples, mosques, churches. Don't allow any new temples, mosques, churches and any type of statues on roads as order given by Honorable Supreme Court of India an interim order on September 29, 2009.

\section{CONCLUSIONS}

If everyone deem regarding this complexity and identify how to understand and genuine trouble and turn into attentive concerning it, the complexity will be tends to reduce. Implementation traffic laws \& rules and are individual task of the sophisticated road users. Zigzag driving should be avoided. If they will travel in right way there will be no delay and overcrowding in metropolitan region. Alternative routes should be provided for two wheelers as they are lashing their vehicles in zigzag manner with unusual speeds on the major roads on metropolitan region. Implementations of the above proposals are very significant and the concern authority/engineer will plan according limited constraints.

\section{REFERENCES:}

[1] Nam, D. H., and Drew, D. R. 1998!. “Analyzing freeway traffic under congestion: Traffic dynamics approach." J. Transp. Eng., 124 3208-212.

[2] Nemeth, Z. A., and Rouphail, N. 1983!. "Traffic control at freeway work sites." J. Transp. Eng., 109 1, $1-15$.

[3] Michalopoulos, P. G., Binseel, E. B., and Papapanou, B. 1978. "Performance

[4] evaluation of traffic actuated signals." Transp. Eng. J. ASCE, 104 5!, 621-636.

[5] R. Sen, P. Siriah, and B. Raman. Roadsoundsense: Acoustic sensing based road congestion monitoring in developing regions. In IEEE SECON, June 2011.

[6] D.J.Dailey, S.D.Maclean, F.W.Cathey, and Z.R.Wall. Transit vehicle arrival prediction: An algorithm and a large scale implementation.Transportation Research Record, (1771), 2001.

[7] Bovy, P., \& Hoogendoorn, S. (2000). "IllPredictabilityof Road Traffic Congestion”. in Bell, M. and Cassir, C.(eds.). Reliability of Transport Networks. Research Studies Press, Baldock, United Kingdom, pp. 43-53.

[8] Wardrop, J. (1952). "Some theoretical aspects of road traffic research". Proceedings of the Institution of Civil Engineers, Part II, 1(36):352-362.

[9] Panwai, S., \& Dia, H. (2005). "Comparative Evaluation of Microscopic Car-Following Behavior". IEEE Transactions on Intelligent Transportation Systems, 6(3), 314-325.

[10]O'Connor, T., \& Wong, H. Y. (2006). "Emergent Properties". Stanford Encyclopaedia of Philosophy. Published online: http://plato.stanford.edu/entries/proper ties-emergent. Accessed February 2010.

[11]Checkland, P. \& Scholes, J. (1990). Soft Systems Methodology in Action. John Wiley \& Sons Inc., Chichester, West Sussex. 
[12]Lewis, T. G. (2009). Network Science: Theory and Applications. John Wiley \& Sons Inc., Hoboken, New Jersey.

[13]Le Bon, G., (1995). The Crowd. Transaction Book, New Brunswick, New Jersey. 